\title{
AVALIAÇÕES EXTERNAS E SUA RELAÇÃO COM O TRABALHO DOCENTE NA PERSPECTIVA DE ATORES DA ESCOLA PÚBLICA
}

\author{
Filippe Rocha DUTRA ${ }^{1}$ \\ Alvanize Valente Fernandes FERENC ${ }^{2}$ \\ Joyce WASSEM ${ }^{3}$
}

\begin{abstract}
Resumo
Este artigo é um recorte da pesquisa que teve por objetivo analisar a relação entre o SIMAVE/PROEB e o trabalho docente, a partir da compreensão de diferentes atores de escolas estaduais pertencentes à Superintendência Regional de Ensino de Muriaé (SRE/Muriaé). A opção pelo SIMAVE como exemplo de avaliação externa deve-se à capilaridade do Sistema Mineiro de Avaliação sobre as escolas públicas do Estado de Minas Gerais. Os resultados obtidos apontam, dentre outros fatores, para uma significativa interferência desse instrumento avaliativo sobre o trabalho docente e sobre o cotidiano das escolas. Destacamos a importância da avaliação e, especificamente, das avaliações externas no contexto educacional, mas evidenciamos a urgente necessidade de se elaborar uma metaavaliação com profunda reflexão dos diferentes atores escolares, sobre o seu papel, a sua contribuição para a educação e a sua validade como instrumento de melhoria da educação.
\end{abstract}

Palavras-chave: Avaliação Externa. SIMAVE. Trabalho Docente. Cotidiano Escolar.

\footnotetext{
${ }^{1}$ Professor da Rede Estadual de Ensino de Minas Gerais. Mestre em Educação pela Universidade Federal de Viçosa (UFV).

E-mail: filippe_rd@hotmail.com

${ }^{2}$ Professora Associada do Departamento de Educação/UFV. Doutora em Educação pela UFSCar e UP/Porto, Portugal.

E-mail: avalenteferenc@gmail.com

${ }^{3}$ Pós-doutoranda em educação pela UFES, bolsista FAPES/CAPES edital N. 010/2018 - PROFIX 2018. Pós-doutora em educação pela UFV e Doutora em educação pela UNICAMP.

E-mail: joywassem@gmail.com
} 


\title{
EXTERNAL ASSESSMENTS AND THEIR RELATION TO TEACHING, FROM THE PERSPECTIVE OF AGENTS IN PUBLIC SCHOOLS
}

\author{
Filippe Rocha DUTRA \\ Alvanize Valente Fernandes FERENC \\ Joyce WASSEM
}

\begin{abstract}
This article is an excerpt of a research that aimed to analyze the relation between SIMAVE/PROEB and the work of teachers, from the viewpoints of different agents in state schools belonging to the Regional Superintendence of Education of Muriaé (SRE/Muriaé). We chose SIMAVE as a subject of external evaluation due to the capillarity of the Minas Gerais Evaluation System on public schools in the State of Minas Gerais. The results point, among other factors, to a significant interference by this evaluation instrument on the work of teachers and on daily life in these schools. We emphasize the importance of assessments and, specifically, of external assessments in the educational context, but we highlight the urgent need to elaborate a meta-assessment, and of profound reflections, by different school agents, on the subjects of its function, its contribution to education, and its validity as a tool for the improvement of education.
\end{abstract}

Keywords: External Assessment. SIMAVE. Educational Work. School Day-to-day. 


\title{
Introdução
}

A emergência da avaliação educacional como tema de interesse nas pesquisas em educação deu-se, no Brasil, de forma mais expressiva, na década de 1990. Até aquele momento, não ocupava lugar de destaque, seja nos currículos dos cursos de Pedagogia, seja nos congressos de educação. Havia, até então, de acordo com Romão (2007), ausência de obras sobre a temática, embora houvesse uma demanda, por parte de educadores, de produções que tratassem do assunto.

Assim, de acordo com esse autor, a ascensão da avaliação como objeto de estudos ocorre em virtude de sua promoção por pesquisadores da área e gestores, adquirindo, inicialmente, status de tema "da moda”. No século XXI, o tema ganha notoriedade, dentre outros motivos, pela cobrança sobre o desempenho dos estudantes e das escolas e sobre os gastos com o ensino formal, bem como pelas reivindicações por mais qualidade na educação, levantadas pelas reformas educacionais recentes (ROMÃO, 2007).

Os estudos de Vianna (1995), Gatti (2002) e Dalben (2005) indicam, com relação à avaliação externa como modalidade e instrumento avaliativo do ensino das instituições e redes, que ela só veio a adquirir sentido e relevância a partir dos últimos anos da década de 1990. As primeiras pesquisas desenvolvidas sobre o tema acabaram contribuindo para que emergisse um novo campo de estudos, tornando-o relevante dentro do meio educacional, seja no âmbito acadêmico/científico, seja no cotidiano das instituições de ensino da educação básica brasileira. Nesse contexto, entende-se por Avaliação Externa:

\begin{abstract}
todo procedimento que comporta, além da avaliação propriamente dita, a medida das proficiências dos alunos em provas padronizadas, o que pode produzir, também, resultados por escolas e redes. No entanto, a caracterização mais saliente para designá-la como externa é o foco de que essa avaliação é empreendida por sujeitos externos ao ambiente escolar. Em face de suas dimensões, geralmente é também chamada de avaliação em larga escala, pois abrange contingente de participantes e fornece subsídios para diversas ações e políticas educacionais para um amplo conjunto de escolas e redes. (MACHADO; ALAVARSE, 2015, p. 69-70)
\end{abstract}

A necessidade de novas formas de se avaliar a educação com exames de larga escala encontrou campo fértil nas mudanças vivenciadas pelo campo educacional nos países de cultura ocidental, a partir das últimas décadas do século XX. No caso do Brasil e da América Latina, dois ciclos de reformas atingiram os países da região: i) a década de 1960, com a ampliação da oferta educacional e; ii) a década de 1990, em que o foco foi na gestão do sistema educacional e na qualidade do que seria ofertado (BORGES, 2016).

Cabe destacar ainda que, no caso brasileiro, a partir dos anos 1980, afloram práticas de avaliação dos sistemas educativos desenvolvidas pelas diferentes redes de ensino espalhadas pelo país, com iniciativas próprias de aparelhos avaliativos por parte dos estados da Federação (SOUSA, 2013) e dos municípios (BAUER et al., 2015), 
impulsionadas por experiências pontuais ocorridas em nível nacional, podendo ser entendidas como as primeiras iniciativas a relacionar a qualidade da educação com a avaliação em larga escala.

Segundo Gatti (2013), a primeira ação ampliada de verificação, tanto da aquisição de conhecimento quanto de sua relação com uma gama de diferentes variáveis, como, por exemplo, o nível econômico, foi a aplicação de prova aos alunos do Ensino Médio, empreendida pela Fundação Getúlio Vargas (FGV), do Rio de Janeiro, em 1966, com a criação do Centro de Estudos de Testes e Pesquisas Psicológicas (CETPP).

Devido à nossa atuação em escolas da Rede Estadual de Ensino de Minas Gerais, em diferentes carreiras do Magistério, com a convivência e diálogo constante com os diferentes atores escolares da educação básica, seja pela prática profissional, seja pela pesquisa, deparamos, na atualidade, com o contínuo movimento de implantação e de influência das avaliações externas nos sistemas de ensino e sua consequente interferência sobre o ambiente escolar.

No contexto de Minas Gerais, Unidade Federativa de vanguarda nos assuntos educacionais, a atual proposta de avaliação do sistema de ensino dá-se pela estruturação de um aparelho avaliativo composto por vários programas e já muito difundido nas escolas do Estado - o Sistema Mineiro de Avaliação e Equidade da Educação Pública (SIMAVE).

O SIMAVE abarca três programas: o Programa de Avaliação da Educação Básica (PROEB), o Programa de Avaliação da Alfabetização (PROALFA) e o Programa de Avaliação da Aprendizagem Escolar (PAAE). Para este estudo, tomamos por objeto de análise o SIMAVE/ PROEB, como um exemplo de avaliação em larga escala.

Como objetivo de pesquisa, procuramos compreender as interferências que as avaliações externas, mais especificamente, o SIMAVE/ PROEB, exercem sobre o trabalho do professor e o cotidiano escolar.

\section{O Sistema Mineiro de Avaliação e Equidade da Educação Pública - SIMAVE}

Instituído pela Resolução $\mathrm{n}^{0}$ 14, de 03 de fevereiro de 2000, com reedição e alteração a partir da Resolução n ${ }^{0}$ 104, de 14 de julho de 2000, o Sistema Mineiro de Avaliação é responsável por dar início a um ciclo de avaliações no estado de Minas Gerais, sob os princípios gerais da descentralização, participação, centralidade da escola, gestão consorciada, formação do professor, equidade, publicidade e independência (MINAS GERAIS, 2000). 
O SIMAVE é uma proposta de avaliação da Secretaria de Estado de Educação de Minas Gerais (SEE/MG), em parceria com o Centro de Políticas Públicas e Avaliação da Educação da Universidade Federal de Juiz de Fora (CAEd/UFJF), ${ }^{4}$ considerada, segundo o Portal Educação/MG, ${ }^{5}$ uma iniciativa que busca examinar as diferentes dimensões do sistema educacional da Rede Estadual de Ensino de Minas Gerais, analisando os resultados alcançados dentro da sala de aula, pela escola, de forma geral, e pelo sistema de ensino, também na ação do corpo docente, na gestão escolar, nas políticas públicas voltadas para a educação e, ainda, no nível de aprendizagem da alfabetização, assim como nos conteúdos básicos aplicados nos níveis de ensino fundamental e médio.

São as chamadas matrizes de referência - conjunto delimitado de habilidades e competências consideradas como essenciais para cada etapa de escolaridade avaliada - que especificam o que será avaliado pelo SIMAVE, levando em consideração as habilidades e os conhecimentos que os alunos de cada série/ano devem possuir.

Sobre o PROEB - foco das nossas discussões - destacamos que se trata de uma avaliação censitária que visa a verificação do desempenho escolar dos alunos da rede pública de ensino (municipal e estadual) de Minas Gerais, a partir das disciplinas de Língua Portuguesa e de Matemática, aplicada aos alunos dos $5^{\circ}$ e $9^{\circ}$ anos do Ensino Fundamental e do $3^{\circ}$ ano do Ensino Médio.

Recentes mudanças, implementadas no período de governo de Fernando Damata Pimentel (2015-2018), trouxeram alterações aos dois principais programas do SIMAVE: PROALFA e PROEB. O primeiro deixa de ter um modelo único de testes e passa a ter dezesseis cadernos de testes diferentes; durante a aplicação das avaliações, o respondente passa a ter autonomia, com itens não lidos pelo professor, o que, antes, acontecia parcialmente; quanto à divulgação dos resultados, passa-se a incorporar os obtidos por alunos indígenas e alunos com deficiência na composição da média (MINAS GERAIS, 2015).

No que se refere, especificamente, ao PROEB, as mudanças foram mais amplas e podem ser sintetizadas no Quadro 1, que se segue:

Quadro 1 - Comparativo das mudanças ocorridas no PROEB a partir de 2015

\begin{tabular}{|l|l|}
\hline \multicolumn{2}{|c|}{ AS MUDANÇAS DO PROEB } \\
\hline Até 2014 & A partir de 2015 \\
\hline
\end{tabular}

\footnotetext{
${ }^{4}$ CAEd/UFJF é referência nacional na execução de programas de avaliação educacional, na formação de especialistas na área de gestão da educação pública e no desenvolvimento de tecnologias de administração escolar. O CAEd atua junto ao Governo Federal, Estados, Municípios, instituições e fundações na realização de avaliações de larga escala com a produção de medidas de desempenho e na investigação de fatores intra e extraescolares associados ao desempenho. O objetivo principal é oferecer dados e informações úteis capazes de subsidiar as ações de melhoria da qualidade da educação e equidade nas oportunidades educacionais (CAED, 2019).

${ }^{5}$ Para mais informações, consultar: http://www2.educacao.mg.gov.br/component/gmg/page/15115simave. Acesso em: 25 jul. 2019
} 


\begin{tabular}{|c|c|}
\hline \multicolumn{2}{|c|}{ ETAPAS E PERIODICIDADE } \\
\hline $\begin{array}{l}5^{\circ} \text { e } 9^{\circ} \text { anos do Ensino Fundamental e } 3^{\circ} \text { ano do } \\
\text { Ensino Médio }\end{array}$ & $\begin{array}{c}5^{\circ}, 7^{\circ} \text { e } 9^{\circ} \text { anos do Ensino } \\
\text { Fundamental e } 1^{\circ} \text { e } 3^{\circ} \text { anos do } \\
\text { Ensino Médio, sendo que em anos } \\
\text { de aplicação da Prova Brasil, o } 5^{\circ} \text { e } \\
9^{\circ} \text { anos não são avaliados pelo } \\
\text { SIMAVE }\end{array}$ \\
\hline \multicolumn{2}{|c|}{ DESENHO DO TESTE } \\
\hline $\begin{array}{c}26 \text { modelos de cadernos com } 39 \text { itens para cada } \\
\text { disciplina avaliada (Língua Portuguesa e } \\
\text { Matemática) }\end{array}$ & $\begin{array}{l}21 \text { modelos de cadernos com } 26 \\
\text { itens para cada disciplina avaliada } \\
\text { (Língua Portuguesa e Matemática) }\end{array}$ \\
\hline \multicolumn{2}{|c|}{ PROCEDIMENTO DE APLICAÇÃO } \\
\hline $\begin{array}{l}\text { Aplicação em dias diferentes, para cada disciplina } \\
\text { avaliada (Língua Portuguesa e Matemática) }\end{array}$ & $\begin{array}{l}\text { Aplicação em único dia, das } \\
\text { disciplinas avaliadas (Língua } \\
\text { Portuguesa e Matemática) seguindo } \\
\text { a aplicação da Prova Brasil. }\end{array}$ \\
\hline \multicolumn{2}{|c|}{ DIVULGAÇÃO DOS RESULTADOS } \\
\hline $\begin{array}{l}\text { Resultados de estudantes com deficiência, de } \\
\text { escolas indígenas e atendimento socioeducativo } \\
\text { divulgados separadamente }\end{array}$ & $\begin{array}{l}\text { Resultados de estudantes com } \\
\text { deficiência, de escolas indígenas e } \\
\text { atendimento socioeducativo } \\
\text { incorporados às médias gerais }\end{array}$ \\
\hline
\end{tabular}

Fonte: Minas Gerais (2015)

Em 2017, por carta oficial encaminhada às escolas da rede estadual de ensino, a SEE-MG reafirma o seu compromisso com as mudanças propostas e lança os chamados Itinerários Avaliativos, com vistas à construção de um plano de ação voltado para cada escola, a partir dos dados fornecidos, também, pelo SIMAVE (MINAS GERAIS/SIMAVE, 2019, s.p.).

A respeito dos Itinerários Avaliativos, é relevante destacar que "Trata-se de um sistema online que reúne informações e indicadores educacionais de toda a rede de ensino para o uso de diferentes públicos como gestores, técnicos da secretaria, diretores escolares, professores e comunidade escolar.” (MINAS GERAIS/SIMAVE, 2019, s.p.)

Mesmo após a mudança de governo, em 2019, a SEE-MG vem atuando - por meio das Superintendências Regionais de Ensino - junto às escolas da rede, de forma a fazer dos espaços destinados às atividades envolvendo, direta e indiretamente, os Itinerários Avaliativos, locais de reflexão, análise e discussão, de forma coletiva, da realidade da escola, do seu processo avaliativo interno e da construção de ações, constantes, voltadas para a melhoria da aprendizagem dos alunos.

Na concepção de uma avaliação externa formada não apenas pela aplicação de testes de desempenho - no caso do SIMAVE, tem relevância o patamar de desempenho no processo de alfabetização, da mesma maneira que em Matemática e em Língua Portuguesa -, mas também com interesse em levantar dados sobre o nível socioeconômico, o perfil do professorado, a caracterização da gestão e infraestrutura da instituição, bem como do percurso escolar dos alunos, são aspectos que, ao longo da existência do SIMAVE, vêm se consolidando. 
As avaliações aplicadas aos alunos apresentam questões de múltipla escolha e seguem o formato metodológico da Teoria da Resposta ao Item (TRI), comumente utilizado pelas avaliações em larga escala.

De acordo com a página oficial da SEE/MG, ${ }^{6}$ a partir dos resultados obtidos pelos alunos nas provas do PROALFA e PROEB é gerada uma proficiência, ${ }^{7}$ lançada numa escala numérica que permite traduzir tal proficiência em um diagnóstico do desempenho escolar, por nível qualitativo, “medindo” os alunos a partir de padrões de desempenho. A escala numérica (régua), no caso do PROEB, vai de 0 a 500 e, no PROALFA, de 0 a 1000, indicando as habilidades e as competências, entre outros itens relativos ao desempenho dos estudantes. (MINAS GERAIS/SIMAVE, 2019)

Os resultados obtidos pelo aluno, pelas turmas e pela escola, de acordo com cada segmento (ano e modalidade de ensino avaliados), podem ser analisados por meio de relatórios emitidos anualmente, meses após a aplicação das avaliações.

\section{O percurso da pesquisa}

Tendo como objeto de estudo o PROEB/SIMAVE e sua relação com o trabalho docente, esta pesquisa foi desenvolvida junto ao Programa de Pós-graduação em Educação, da Universidade Federal de Viçosa-MG.

A pesquisa teve abordagem qualitativa, uma vez que se alicerça na preocupação em compreender melhor o objeto de estudo, dentro do contexto em que se insere, e a partir da perspectiva dos atores diretamente envolvidos com ele (GODOY, 1995), levando em consideração o que pensam sobre o fenômeno estudado.

Para a coleta de dados, utilizamos um questionário com questões abertas e fechadas (com as opções: concordar plenamente; concordar parcialmente; não concordar e; não saber responder), aplicado a 62 atores escolares, de três escolas estaduais, localizadas em diferentes Municípios do estado de Minas Gerais, mas todas pertencentes à mesma Superintendência de Ensino. Os 62 participantes eram: professores que atuavam a partir do $6^{\circ}$ ano do Ensino Fundamental até o $3^{\circ}$ ano do Ensino Médio regular; professores da Educação de Jovens e Adultos; professores de apoio, da educação especial; professores do uso da biblioteca; supervisores; vicediretores e diretores de escola.

Destacamos que, em razão dos limites de tempo para o desenvolvimento da pesquisa, optamos por selecionar, como participantes, os diferentes segmentos de profissionais da educação, não incluindo alunos e pais/responsáveis por alunos.

\footnotetext{
${ }^{6}$ Para mais informações, consultar: http://simave.educacao.mg.gov.br/. Acesso em: 30 nov. 2019.

7 “A medida de proficiência é produzida a partir dos resultados dos estudantes nos testes do Proalfa e do Proeb. Esses resultados são colocados em uma escala numérica, a qual permite traduzir medidas (proficiência) em diagnósticos qualitativos do desempenho escolar.” (MINAS GERAIS, 2015, p. 7)
} 
Um critério fundamental para a escolha das escolas participantes foi o fato de oferecerem as modalidades de ensino avaliadas pelo SIMAVE/PROEB: os anos finais do Ensino Fundamental e o Ensino Médio. Nenhuma das escolas selecionadas ofertava os anos iniciais do Ensino Fundamental.

Após a aplicação dos questionários, realizamos entrevistas individuais com 05 atores escolares que, após participarem da primeira etapa (aplicação do questionário), aceitaram também colaborar na fase da entrevista. Cabe destacar que as três escolas estiveram representadas nessa fase da pesquisa. Os participantes da entrevista foram selecionados a partir da função/cargo exercida(o), a saber: um(a) professor(a) de Língua Portuguesa; um(a) professora(a) de Matemática; um(a) diretor de escola; um(a) supervisor e um(a) professor(a) de área não avaliada pelo SIMAVE/PROEB.

Procuramos selecionar profissionais atuantes em áreas diferenciadas, com o intuito de coletar informações a partir de segmentos distintos da carreira do magistério. Sendo assim, o universo de 05 participantes selecionados para as entrevistas foi composto por uma diretora, uma supervisora, duas professoras e um professor.

Cabe reforçar que a manutenção de 5 participantes na fase das entrevistas justificase pela abordagem qualitativa da pesquisa e pela própria análise de conteúdo, bem como pela proposta de ouvir os diferentes atores escolares que, uma vez inseridos nesta pesquisa, tornaram-se porta vozes de seus pares, segmentos e/ou áreas de atuação.

Os dados coletados foram compilados a partir da análise de conteúdo, entendida por Moraes (1999, p. 2) como "[...] uma metodologia de pesquisa usada para descrever e interpretar o conteúdo de toda classe de documentos e textos”. Conforme proposto na fundamentação dessa metodologia, o conteúdo analisado passou pelas três fases: descrição, inferência e interpretação. Para o tratamento dos dados, a técnica da análise temática ou categorial utilizada baseia-se em operações de desmembramento do texto em unidades, ou seja, descobrir os diferentes núcleos de sentido que constituem a comunicação e, posteriormente, realizar o seu reagrupamento em classes ou categorias. (BARDIN, 2004)

Desse modo, os dados analisados permitiram elencar oito categorias: i) Percepção sobre Avaliação Externa: as vozes dos atores escolares; ii) Imagem do SIMAVE/PROEB; iii) Avaliação Externa e Qualidade da Educação; iv) SIMAVE/PROEB e Competição no Contexto Escolar; v) SIMAVE/PROEB e Cotidiano Escolar; vi) Cobrança e Responsabilização no Ambiente Escolar; vii) Relação SIMAVE/PROEB e Trabalho Escolar; e viii) Estratégias Escolares e o SIMAVE/PROEB.

Nos limites deste artigo, exploramos duas categorias: "SIMAVE/PROEB e Cotidiano Escolar" e "SIMAVE/PROEB e Competição no Contexto Escolar". Essas duas categorias e suas respectivas subcategorias convergem para a discussão sobre o envolvimento e a ação do Sistema Mineiro de Avaliação com e no cotidiano escolar. 
Após quase três décadas de sua implantação, como tem se comportado o SIMAVE/PROEB dentro do contexto escolar e qual a sua interferência sobre o dia a dia das escolas, são questões norteadoras da reflexão apresentadas a seguir.

\title{
SIMAVE/PROEB e Cotidiano Escolar
}

Os atores escolares participantes da pesquisa foram indagados se 0 SIMAVE/PROEB influenciaria nas atividades por eles desenvolvidas no cotidiano escolar. Tivemos as seguintes respostas: 35,5\% disseram que influencia parcialmente; 32,3\% responderam que influencia, ao passo que 21\% disseram que não influencia e; $11,2 \%$ não souberam responder.

A título de ratificação do que já foi apontado, quando questionados se o SIMAVE/PROEB influencia nas avaliações internas da escola: 41,9\% responderam que sim; 27,4\% disseram que influencia parcialmente; 19,4\% não souberam responder e; 11,3\% afirmaram que não influencia. Seguindo a mesma linha de investigação, quando indagados se o SIMAVE/PROEB tem influência sobre as atividades desenvolvidas pela escola: 43,5\% disseram que parcialmente; 32,3\% disseram que sim; $21 \%$ não souberam responder e; somente 3,2\% disseram que não tem influência.

A partir dos dados que indicaram a influência do SIMAVE/PROEB sobre as práticas escolares, buscamos, junto aos participantes, aprofundar o tema na entrevista, visando explorar quais práticas são comuns dentro das escolas, diante da existência desse formato de avaliação educacional.

Uma das condutas presentes no dia a dia das escolas, a partir da existência e da ingerência de um modelo de avaliação externa em uma rede de ensino, é a prática da análise e exposição dos resultados obtidos nos exames, o que perpassa diferentes momentos, envolvendo os diversos segmentos da comunidade escolar, com o objetivo de dar destaque aos resultados obtidos pela escola e promover uma reflexão sobre eles. Durante as entrevistas, os participantes expuseram esta questão, como demonstram as falas a seguir:

\begin{abstract}
- É feita reunião. Tem até dias específicos que a gente reúne e é apresentado para nós todos aqueles resultados, [...] a gente reúne em grupos, faz análise e depois a gente ainda traz a comunidade e explica para a comunidade o resultado da escola (P2).

- Existem etapas. [...] primeiramente, reunião pedagógica, colocar os professores bem a par do que vai acontecer e intensificar mesmo essa questão de sala de aula com os alunos [...] e, mediante a posse dos resultados, a gente faz um gráfico, analisando isso em reunião também, depois faz uma chamada mais pública, com a comunidade escolar toda e a gente vê o que pode melhorar mediante isso (P4).
\end{abstract}

O contato da escola com os resultados do SIMAVE, portanto, é notório. Momentos de análise dos resultados também ocorrem com frequência nas instituições de ensino que participaram desta pesquisa. Entretanto, sabemos que, para além da participação nas avaliações, o acesso a uma análise mais aprofundada dos resultados e 
aos seus significados nos parece limitado. Reflexões sobre essas avaliações no contexto escolar e sua interferência na atividade docente são pontos que também merecem atenção.

Para Carvalho et al. (2011), que discutem o olhar das escolas para os resultados obtidos nas avaliações do SIMAVE, as instituições de ensino têm acesso aos resultados, há espaços para a que sejam discutidos, incluindo reuniões com essa finalidade. Tais resultados são divulgados na comunidade escolar, embora haja registros de que isso não aconteça em todas as instituições de ensino.

Outra conduta comum, dentro das escolas, a partir da incidência dos testes de larga escala é o hábito de se elaborar e executar práticas de ensino a partir dos resultados alcançados pela instituição no SIMAVE/PROEB. Ou seja, o que tem sido feito e o que pode ser realizado dentro das escolas, a partir dos resultados das avaliações impõem-se como pontos a discutir, para o que corrobora o depoimento a seguir:

Tenho dúvidas, após o trabalho de análise, se o que fazemos está funcionando, uma vez que tentamos resolver os problemas das questões do SIMAVE/PROEB, com seus parâmetros e o que é cobrado a partir disso. E o que está fora deste contexto? Não temos ações voltadas para isto. Penso que deveríamos trabalhar de forma diferente, complementar [...] pensando também a partir do que os alunos vivem e são (P3).

O passo seguinte à análise dos resultados é uma questão que merece especial atenção. Afinal, de que adianta o acesso e uma averiguação do que os alunos conseguiram produzir nas avaliações externas se os passos seguintes - intervenção e apontamento de práticas que vão atacar as falhas apontadas pelos testes, - não são pensados de forma concreta e colocados em prática?

O que nos parece é que não há um trabalho contínuo a partir dos resultados das avaliações, seja pelo acúmulo de funções dos professores, pela carência de tempo, ao longo do ano letivo, para estudos continuados de aprofundamento sobre o assunto, seja ainda por uma falha no próprio sistema que propõe a avaliação, estimula a preparação dos alunos para os testes, organiza e aplica as avaliações, faz questão de propagar os resultados e propor uma reflexão inicial, mas que ainda carece de melhores instrumentos de acompanhamento contínuo do que pode ser feito a partir dos resultados.

O estudo de Carvalho et al. (2011) salienta que há uma certa dificuldade, de supervisores e orientadores pedagógicos, em trabalhar com os resultados. Registra-se a tendência de um distanciamento entre os profissionais da escola e os órgãos de planejamento central, além do fato de que as discussões dos resultados se dão “[...] sem muita possibilidade de aprofundamento, pois a ênfase se situa mais nos gráficos, nas tabelas e nas metas em detrimento das dificuldades concretas existentes na realidade de cada escola." (CARVALHO et al. 2011, p. 117)

Podemos perceber, pelo estudo de Carvalho (2011) e pelos dados desta pesquisa, que pouco tem sido feito nas escolas a partir dos resultados obtidos nas avaliações do 
SIMAVE/PROEB. Embora com mais de 15 anos de sua implantação, um maior e mais aprofundado conhecimento sobre esse Sistema de Avaliação - incluindo um posicionamento mais claro quanto ao seu papel dentro da educação mineira - é algo que carece de especial atenção, como sugere a fala de um dos participantes da entrevista:

Eu acho complicado de ser feito muita coisa, porque geralmente esses resultados saem no ano seguinte, porque a prova geralmente é feita no final do ano. Acho que depois que passa muito tempo, acho que acaba se perdendo (P5).

O “treinamento" dos alunos para participarem das avaliações externas pode ser apontada como um exemplo de outra prática, existente no contexto escolar, fruto da presença dos testes de larga escala. A seguir, destacamos duas falas de participantes da entrevista que elucidam essa questão:

Tem outro tipo de preparação, [...] feita através das nossas atividades, [...] a gente prepara esse aluno anteriormente à prova do SIMAVE [...]. Além dos nossos conteúdos, nós treinamos eles. Eu digo isso pelos professores todos, porque nós somos orientados a fazer isso. Nós fazemos atividades, realmente, para preparar os alunos para chegar até o SIMAVE. Não quer dizer que essa atividade seja especificamente só para o SIMAVE, porque são questões desenvolvidas dentro dos nossos conteúdos, do nosso dia a dia [...] mas elas são sim voltadas para que esse aluno tenha um melhor desempenho no SIMAVE (P3).

Primeiramente a gente tem uma preparação desses meninos, uma chamada para estas avaliações sistêmicas e, em seguida, começam as preparações [...], intensificando mesmo essa questão de sala de aula com os alunos, até, às vezes, extra turno, na aprendizagem, no reforço dessa aprendizagem [...]. A gente tem os caderninhos das avaliações anteriores e os professores retomam essas questões e intensificam esse trabalho em sala de aula. Quando há uma possibilidade de fazer isso extra turno, é feito, quando não é, fica só restrito à sala de aula (P4).

Não são poucos os professores e as escolas que pautam seus trabalhos pelos resultados obtidos nas avaliações do SIMAVE e que, por isso, acabam preparando os seus alunos para obterem um desempenho satisfatório nesses testes, com vistas, inclusive, ao alcance de metas traçadas (CARVALHO et al. 2011). Ao mesmo tempo que - como aponta a pesquisa realizada por Borges e Sá (2015) - uma grande parcela dos professores participantes indica que apostam em incentivar, sem distinção, os seus alunos (88,3\%), bem como em prepará-los para as avaliações, incluindo estratégias como a utilização de materiais disponibilizados pela Secretaria de Estado de Educação/MG e testes similares aos das avaliações do SIMAVE.

Fazemos aqui algumas provocações: se há a prática de "treinamento" dos alunos e se, mesmo assim, os resultados, por vezes, não são satisfatórios, podemos dizer que esses mesmos "treinamentos" estariam se revelando ineficazes e que, também, precisariam ser revistos? Outras estratégias de ensino poderiam ser construídas? Qual a finalidade dessas avaliações?

Borges e Sá (2015, p. 2), citando pesquisas desenvolvidas no cenário educacional dos Estados Unidos, por Madaus, Russell e Higgins (2009), destacam que:

Testes de alto impacto são paradoxais, na medida em que são políticas públicas bem intencionadas, mas com consequências negativas não 
intencionais. Constatam que, entre outras consequências, em função da pressão sobre os professores para melhorarem o desempenho dos alunos, os testes têm: a) Influenciado as práticas de ensino, levando os professores a focar o trabalho nas disciplinas e habilidades que possibilitam a preparação dos alunos para as provas.

A preparação dos alunos para a participação em avaliações de larga escala, feita pela escola, também é citada por Bonamino e Sousa (2012), quando elucidam que tais exames, ao serem utilizados como políticas de responsabilização dos atores escolares, acabam por levar esses mesmos atores a alinharem seus alunos para esses momentos.

A questão da preparação dos alunos para as avaliações do SIMAVE é ponto que merece destaque e pode, inclusive, gerar opiniões divergentes. Afinal, ao mesmo tempo em que essas avaliações se apresentam como instrumentos extrínsecos de averiguação do trabalho desenvolvido nas escolas, elas resultam em uma ferramenta introduzida nas instituições de ensino sem uma preparação e discussão apropriadas junto aos profissionais dessas escolas. Assim, as avaliações em larga escala acabam por gerar tensões no ambiente escolar quando introduzem, nesse espaço, metas e padrões a serem alcançados que são elaborados e propostos por agentes externos.

\section{SIMAVE/PROEB e Competição no Contexto Escolar}

Durante a pesquisa, buscamos investigar, também, a influência do SIMAVE/PROEB sobre um dos pilares relevantes para o contexto educacional: as relações profissionais, entre os professores, entre a escola e a superintendência regional de ensino e entre as superintendências. Queríamos compreender a possibilidade de que a influência do Sistema Mineiro de Avaliação acabe por fomentar competições, dentro da escola e/ou entre as escolas ou, ainda, entre as superintendências.

Registramos que a hipótese de uma possível premiação e/ou pontuação ofertadas pela escola aos alunos por sua participação nas avaliações não é mencionada por nenhum dos atores escolares participantes desta pesquisa.

Para três dos entrevistados, há comparações entre os resultados obtidos nas avaliações. É uma prática recorrente dentro do ambiente escolar, impulsionada pela existência dos testes padronizados.

Há, portanto, uma disputa, uma comparação de resultados, seja entre as escolas, seja dentro de uma escola. Segundo os participantes da pesquisa, há ansiedade nos momentos que antecedem a divulgação inicial dos resultados e, tão logo as escolas estejam de posse deles, inicia-se um processo interno de comparação entre os resultados obtidos pela instituição nos anos anteriores, mas também com relação aos alcançados pelas outras escolas. Afinal, fazer parte de uma instituição de ensino cuja nota no SIMAVE/PROEB seja expressiva frente às demais, é motivo de satisfação, de elogios e de algum reconhecimento, como demonstram as falas transcritas a seguir: 
A gente fica, assim, ansioso pra sair esse resultado. [...] sempre que o resultado chega, a gente procura trabalhar com os professores [...] e também a gente faz essa comparação: superintendência, secretaria e escola. A gente compara. [...] Eu acho que fomenta, porque querendo ou não as pessoas comentam os resultados. [...] Gera sim uma competição (P1).

Eles querem provocar isso nas nossas escolas [...]. O que nós sentimos, como professores, quando nós recebemos esses resultados é que estar em uma escola que tem uma nota melhor no SIMAVE/PROEB, para a superintendência, é muito bom. Então, independe se a escola está fazendo um trabalho efetivo ou é realmente uma escola boa e que propõe excelentes trabalhos. Depende, para superintendência, se a escola tem uma nota boa no SIMAVE/PROEB (P3).

As avaliações do SIMAVE/PROEB, mesmo em seu formato atual, que prioriza outros aspectos ${ }^{8}$ de interesse do Sistema Mineiro de Avaliação, ainda remete, as escolas e os seus funcionários, a um olhar diferenciado para tais práticas avaliativas. Como já apontado, há a prática da divulgação dos resultados para a comunidade escolar, inclusive, em dia específico, previsto no calendário letivo. Há que se observar, ainda, que a metodologia de apresentação dos resultados, queira ou não, acaba por gerar algum interesse por comparações, visto que o resultado da escola é divulgado, por meio de uma tela, juntamente com a média dos resultados obtidos pela Superintendência de Ensino da qual a escola faz parte, além da média geral do Estado de Minas Gerais.

Sobre o SIMAVE/PROEB, mesmo considerando que a prática da criação de rankings não ocorre de forma tão explícita, compartilhamos o que dizem Alavarse et al. (2017, p. 13) em relação à Prova Brasil e ao Índice de Desenvolvimento da Educação Básica (Ideb), apontando que a divulgação desse resultados:

[...] tem ensejado, ainda que não oficialmente, a elaboração de um ranking das melhores (e consequentemente das piores) escolas e redes do país, algo que, desconectado de outras análises, pode ser considerado um equívoco, pois impele escolas e redes à competição desprovida de um estudo minucioso da realidade educacional e suas dificuldades, sem a contextualização desses resultados.

Nesse contexto, vale destacar que Novaes (2014, p. 284) refere-se à avaliação em larga escala como uma prática inserida no “[...] seio das políticas de 'quase mercado', principalmente quando se trata de incorporar o modelo de gestão empresarial à gestão pública, tendo como referência os resultados de testes padronizados”.

O conceito de "quase mercado", que encontrou amparo nas políticas de avaliação em larga escala, como via de convencimento da sociedade em geral a respeito de sua legitimidade e viabilidade como aparato de indução por melhorias na educação, é amplamente discutido por autores como Freitas (2013) e Gatti (2013). Os autores chamam a atenção para o quanto a lógica neoliberal já se infiltrou no setor educacional com a inserção, não somente dos exames externos - que servem para

${ }^{8}$ Podemos citar, como exemplo de aspectos de interesse do Sistema de avaliação, a diminuição das desigualdades educacionais vivenciadas no Estado (enfoque da equidade) e um maior diálogo entre as avaliações externas e as internas, por meio de práticas autoavaliativas e de planejamento das atividades a serem realizadas na escola (enfoque pedagógico), cujo lema é "Nenhum estudante a menos e todos aprendendo mais.” (MINAS GERAIS, 2015) 
medir e legitimar as práticas contemporâneas e justificar políticas públicas respaldadas pela tão proclamada qualidade da educação -, mas também de índices e metas a serem alcançados, em rankings que geram competição entre países, redes de ensino, escolas, professores e alunos, bem como de sistemas de bonificação baseados nos resultados obtidos nos testes de larga escala.

Chama-nos a atenção que não tenha sido citada, pelos participantes desta pesquisa, a política de bonificação, ou seja, a política meritocrática de Minas Gerais, regulamentada ${ }^{9}$ pela Lei nº 17.600/2008, referenciada por Moreira (2019), que regularizava o pagamento de prêmio por produtividade aos servidores públicos de escolas estaduais que alcançassem as metas estabelecidas pelo governo.

O SIMAVE/PROEB e a Prova Brasil são avaliações censitárias que primam por objetivos comuns aos mesmos ideais e, nesse sentido, acabam por representar, cada um desses modelos na sua esfera de atuação, um mesmo padrão de avaliação.

Cabe, porém, enfatizar que, enquanto alguns participantes da pesquisa entendem que há competição, outros indicam que não há, no âmbito escolar, competição fomentada pelos resultados aferidos nas avaliações, denotando que não há uma posição unânime entre os participantes. Desse modo, os participantes que afirmam não vislumbrarem tal prática nas escolas, quando o ponto central são as avaliações do SIMAVE/PROEB, ressaltam que:

A gente analisa, a gente fica feliz com o resultado da gente, se for melhor. Se for pior a gente vai corrigir, vai procurar reunir todo mudo, [...] tentando melhorar o nosso resultado. O resultado da escola do lado de lá, se está baixo, a gente fica triste; se tiver bom, serve de modelo para a gente, mas a gente não tem essa competição, essa inveja de que fulano tem que ser melhor do que ciclano (P2).

Esta percepção contrasta com a apresentada anteriormente e nos faz refletir sobre o quanto já estão adaptados, vários atores escolares, às políticas de avaliação, especialmente de larga escala. O que merece uma discussão aprofundada em produções futuras, tendo em vista o recorte e os limites deste artigo.

Embora a gestão governamental estadual, de 2015 a 2018, tenha implementado mudanças no Sistema Mineiro de Avaliação que buscaram afastá-lo da prática de "ranqueamento", ainda questionamos o quanto se fazem presentes as formas implícitas de fomento à competição e à busca por melhores resultados. Não há registro da existência de um ranking oficial, das escolas e seus resultados, por parte da Secretaria Estadual de Educação. Entretanto, não alcançar os resultados dentro das metas traçadas ou estar abaixo da média obtida pela superintendência de ensino à qual uma escola faz parte, pode interferir, por exemplo, na escolha daquela escola por parte das famílias, especialmente, daquelas culturalmente mais favorecidas, o que pode resultar em um cenário com menor

9 Essa política de bonificação foi revogada no ano de 2016, por meio da Lei da Reforma Administrativa, a Lei Estadual $n^{\circ} 22.257 / 2016$, por entender que era inviável financeiramente para a Administração Pública (MOREIRA, 2019). 
número de matrículas e, consequentemente, de investimento (NOGUEIRA; LACERDA, 2014).

\section{Considerações finais}

O SIMAVE/PROEB, como exemplo de avaliação externa, é uma realidade, presente nas escolas mineiras, há quase duas décadas e, nos últimos anos, sua relevância para o processo avaliativo da rede estadual de ensino é notória. Estamos nos referindo a um exemplo de avaliação externa, já introduzida e, de alguma forma, familiar aos diferentes atores escolares, mas não, necessariamente, compreendida do mesmo modo por todos esses atores.

A pesquisa demonstrou, ainda, a dificuldade de conciliar os resultados obtidos nas avaliações com as práticas pedagógicas a serem vivenciadas, posteriormente, dentro das escolas. Há a preocupação em preparar os alunos para os testes, em analisar os pontos fortes e fracos da escola e, até mesmo, em tentar intervir para que, no próximo ano, os desacertos sejam corrigidos. Porém, a conclusão a que se chega é a de que há uma dificuldade em transcender o estreito divisor de águas entre o que se tem feito para alcançar os melhores resultados nas avaliações do SIMAVE/PROEB e o que se pode fazer para que se alcance maior eficácia no processo de ensino e aprendizagem dos alunos.

Contudo, é importante elucidar que as avaliações externas têm sua relevância no processo de ensino e aprendizagem, seja por trazer um panorama da rede, de cada escola ou aluno, seja por servir de instrumento que auxilia na verificação das políticas desenvolvidas com apontamentos para possíveis alterações de estratégias e percursos. Entretanto, também fazemos questão de enfatizar que, no formato e na dimensão que, na atualidade, as concebemos e percebemos, as avaliações externas acabam sendo concebidas como um ponto nevrálgico da educação. De instrumento do processo de ensino, tornou-se matéria crucial e central. De ferramenta construída para auxiliar, tornou-se ponto principal, com grande capacidade de influenciar pautas e processos educativos.

O que fica para nós, em toda essa discussão, é que, enraizada ou não nas escolas, discutida ou não pelos diferentes atores escolares, relacionada ou não à prática docente, a avaliação externa é uma realidade imposta, pela hierarquia institucional, ao contexto escolar e, assim, não se pode negar a sua influência e interferência, tanto nas atividades desenvolvidas pelos profissionais da educação quanto na própria organização, na estruturação e nos arranjos que permeiam as carreiras do magistério.

Evidencia-se, assim, a urgente necessidade de se elaborar a meta-avaliação e uma profunda reflexão sobre as avaliações externas, por parte dos diferentes atores escolares, 
sobre o seu papel, as suas contribuições para a educação e a sua validade como instrumento de melhoria na qualidade da educação.

\section{Referências}

ALVES-MAZZOTTI, Alda Judith; GEWANDSZNAJDER, Fernando. O método nas ciências naturais e sociais - pesquisa quantitativa e qualitativa. 2. ed. São Paulo: Pioneira/Thomson, 2002. 203p.

BARDIN, L. Análise de conteúdo. Edição Revista e Atualizada. Lisboa: Edições 70, 2004.

BAUER, Adriana et al. Avaliação em larga escala em municípios brasileiros: o que dizem os números? Estudos em Avaliação Educacional, São Paulo, v. 26, n. 62, p. 326-352, maio/ago. 2015. Disponível em: http://publicacoes.fcc.org.br/ojs/index.php/eae/article/view/3207. Acesso em: 18 nov. 2019.

BONAMINO, Alicia Maria Catalano de; SOUSA, Sandra Zákia. Três gerações de avaliação da educação básica no Brasil: interfaces com o currículo da/na escola. Educação e Pesquisa, São Paulo, v. 38, n. 2, p. 373-388, abr./jul. 2012. Disponível em: http://www.scielo.br/pdf/ep/v38n2/ aopep633.pdf. Acesso em: 27 nov. 2019

BORGES, Edna; SÁ, Virgínio. As consequências das avaliações externas em larga escala no trabalho docente. Revista de estudios e investigación em Psicología y educación, Conuña, n. 10, p. 106-110, 2015. Disponível em: http://revistas.udc.es/index.php/reipe/article/view/reipe. 2015.0.10.579/pdf_275. Acesso em: 02 nov. 2019.

BORGES, Edna Martins. Avaliações externas em larga escala no contexto escolar: percepções dos diretores escolares da rede estadual de ensino de Minas Gerais. 2016. 314f. Tese (Doutorado em Educação) - Universidade Federal de Minas Gerais/ Faculdade de Educação, Belo Horizonte, 2016.

CAED/UFJF. Centro de Políticas Públicas e Avaliação da Educação. Disponível em: http://institucional.caed.ufjf.br/o-que-fazemos/. Acesso em: 29 jul. 2019.

CARVALHO, Stella Willians et al. O Sistema Mineiro de Avaliação da Educação Pública: a percepção dos profissionais das escolas públicas estaduais de Belo Horizonte. Periódicos UEMG, Belo Horizonte, ano 14, n. 18, p. 97-121. dez. 2011. Disponível em: http://revista.uemg.br/ index.php/educacaoemfoco/article/view/233. Acesso em: 07 nov. 2019

DALBEN, Ângela Imaculada Loureiro de Freitas. Avaliação sistêmica. Presença Pedagógica, Belo Horizonte, v. 11, n. 65, p. 74-80, 2005. Disponível em: https://www.linhadiretadigital.com.br/portal /\#/materiarevista/394. Acesso em: 28 out. 2019.

FREITAS, Luiz Carlos de. Caminhos da avaliação de sistemas educacionais no Brasil: o embate entre a cultura da auditoria e a cultura da avaliação. In: BAUER, Adriana; GATTI, Bernadete Angelina (org.). Ciclo de debates: vinte e cinco anos de avaliação de sistemas educacionais no Brasil - implicações nas redes de ensino, no currículo e na formação de professores. Florianópolis, Editora Insular, 2013. p. 147-176.

GATTI, Bernardete Angelina. Avaliação educacional no Brasil: pontuando uma história de ações. EccoS revista científica, São Paulo, v. 4, n. 1, p. 17-41, 2002. Disponível em: https: //periodicos.

uninove.br/index.php?journal=eccos\&page=article\&op=view\&path\%5B\%5D=291\&path\% 5B\%5D=280. Acesso em: 25 out. 2019. 
GATTI, Bernardete Angelina. Possibilidades e fundamentos de avaliações em larga escala: primórdios e perspectivas contemporâneas. In: BAUER, Adriana; GATTI, Bernadete Angelina; TAVARES, Marialva Rossi (org.). Ciclo de debates: vinte e cinco anos de avaliação de sistemas educacionais no Brasil - origens e pressupostos, v. 1. Florianópolis: Editora Insular, 2013, p. 47-69.

GODOY, Arilda Schmidt. Pesquisa qualitativa: tipos fundamentais. Revista de Administração de Empresas. São Paulo, v. 35, n. 3, p. 20-29, maio/jun. 1995. Disponível em: http://www.scielo.br/ pdf/rae/v35n3/a04v35n3.pdf. Acesso em: 15 jul. 2019.

MACHADO, Cristiane; ALAVARSE, Ocimar Munhoz. Responsabilização ou controle da qualidade do ensino: a que serve a avaliação externa? Educação: teoria e prática, Rio Claro, v. 25, n. 48, p. 67-79, jan./abr. 2015. Disponível em: https://www.periodicos.rc.biblioteca.unesp.br/ index.php/educacao/article/view/7856. Acesso em: 20 set. 2019.

MINAS GERAIS. Resolução $n^{o}$ 104, de 14 de julho de 2000. Reedita, com alterações, a Resolução $\mathrm{n}^{\circ}$ 14, de 03 de fevereiro de 2000, que instituiu o Sistema Mineiro de Avaliação da Educação Pública - SIMAVE e cria o Programa de Avaliação da Rede Pública de Educação Básica - PROEB. Belo Horizonte, 14 de julho de 2000. Disponível em: http://pesquisalegislativa.mg.gov.br/ LegislacaoCompleta.aspx?cod=23380\&marc. Acesso em: 29 jul. 2019.

MINAS GERAIS. SIMAVE: divulgação e apropriação dos resultados - SIMAVE 2015. Belo Horizonte, 2015.

MINAS GERAIS/SIMAVE: revista da avaliação. Disponível em: http://www.simave.caedufjf.net/ revista/. Acesso em: 02 set. 2019.

MORAES, Roque. Análise de conteúdo. Revista Educação, Porto Alegre, v. 22, n. 37, p.7-32, 1999. Disponível em: https://edisciplinas.usp.br/pluginfile.php/4125089/mod_resource/content/1/RoqueMoraes_Analise\%20de\%20conteudo-1999.pdf. Acesso em: 15 set. 2019.

MOREIRA, Andréa Renó Jorge. Avaliações externas e responsabilização docente: visões e implicações no cotidiano de escolas públicas. 2019. 156 f. Dissertação (Mestrado em Educação) - Universidade Federal de Viçosa, Viçosa, 2019.

NOGUEIRA, Maria Alice; LACERDA, Wania Maria Guimarães. Os rankings de estabelecimentos de ensino médio e as lógicas de ação das escolas: o caso do Colégio de Aplicação da Universidade Federal de Viçosa. In: KRAWZCYK, Nora (org.). Sociologia do Ensino Médio: Crítica ao economicismo na política educacional. 1. ed. São Paulo: Cortez Editora, 2014. p. 127-162.

NOVAES, Luiz Carlos. Os impactos da avaliação externa sobre o trabalho de professores na rede estadual paulista. Roteiro, Joaçaba-SC, v. 39, . 2, p. 283 310, jul./dez. 2014. Disponível https://portalperiodicos.unoesc.edu.br/roteiro/article/view/4283/pdf_33. Acesso em: 15 jul. 2019.

ROMÃO, José Eustáquio. Avaliação: exclusão ou inclusão? In: MELO, Marcos Muniz (org.). Avaliação na educação. Pinhais: Editora Melo, 2007. p. 57-61.

SOUSA, Sandra Maria Zákia Lian. Avaliação externa e em larga escala no âmbito do Estado Brasileiro: interface de experiências estaduais e municipais de avaliação da educação básica como iniciativas do Governo Federal. In: BAUER, Adriana; GATTI, Bernadete Angelina (Org.). Ciclo de debates: vinte e cinco anos de avaliação de sistemas educacionais no brasil - implicações nas redes de ensino, no currículo e na formação de professores, Volume 2, Florianópolis: Editora Insular, 2013, p. 61-85.

VIANNA, Heraldo Marelim. Avaliação educacional: uma perspectiva histórica. Estudos em Avaliação Educacional. São Paulo, n. 12, p. 7-24, jul./dez. 1995. 


\section{EDUCAC̄Ã0}

Avaliações externas e sua relação com o trabalho docente na perspectiva de atores da escola pública

Disponível

em:

http://publicacoes.fcc.org.br/ojs/index.php/eae/article/view/2297/2248. Acesso em: 31 jul. 2019.

Recebido em: 09/06/2019

Aprovado em: 06/04/2020 